\title{
ACCELERATION OF SMALL, LIGHT PROJECTILES (INCLUDING HYDROGEN ISOTOPES) TO HIGH SPEEDS USING A TWO-STAGE LIGHT GAS GUN*
}

\author{
S. K. Combs, C. R. Foust, M. J. Gouge, and S. L. Milora
}

Oak Ridge National Laboratory, Oak Ridge, Tennessee 37831-8071

\section{DISCLAIMER}

This report was prepared as an account of work sponsored by an agency of the United States Government. Neither the United States Government nor any agency thereof, nor any of their employees, makes any warranty, express or implied, or assumes any legal liability or responsibility for the accuracy, completeness, or usefulness of any information, apparatus, product, or process disclosed, or represents that its use would not infringe privately owned rights. Reference hercin to any specific commurcial product, process, or service by trade name, trademark, manufacturer, or otherwise does not necessarily constitute or imply its endorsement, recommendation, or favoring by the United States Government or any agency thereof. The views and opinions of authors expressed herein do not necessarily state or reflect those of the United States Government or any agency thereof.

"Research sponsored by the Office of Fusion Energy, U.S. Department of Energy, under contract DE-ACO584OR21400 with Martin Marietta Energy Systems, Inc. 


\title{
ACCELERATION OF SMALL, LIGHT PROJECTILES \\ (INCLUDING HYDROGEN ISOTOPES) TO HIGH SPEEDS \\ USING A TWO-STAGE LIGHT GAS GUN*
}

\author{
S. K. Combs, C. R. Foust, M. J. Gouge, and S. L. Milora \\ Oak Ridge National Laboratory, Oak Fidge, Tennessee 37831-8071
}

Small, light projectiles have been accelerated to high speeds using a twostage light gas gun at Oak Ridge National Laboratory. With 35-mg plastic projectiles ( $4 \mathrm{~mm}$ in diameter), speeds of up to $4.5 \mathrm{~km} / \mathrm{s}$ have been recorded. The "pipe gun" technique for freezing hydrogen isotopes in situ in the gun barrel has been used to accelerate deuterium pellets (nominal diameter of $4 \mathrm{~mm}$ ) to velocities of up to $2.85 \mathrm{~km} / \mathrm{s}$. The primary application of this technology is for plasma fueling of fusion devices via pellei injection of hydrogen isotopes. Conventional pellet injectors are limited to pellet speeds in the range $1-2 \mathrm{~km} / \mathrm{s}$. Higher velocities are desirable for plasma fueling applications, and the two-stage prieumatic technique offers performance in a higher velocity regime. However, experimental results indicate that the use of sabots to encase the cryogenic pellets and protect them from the high peak pressures will be required to reliably attain intact pellets at speeds of $\approx 3 \mathrm{~km} / \mathrm{s}$ or greater. In some limited tests, lithium hydride pellets were accelerated to speeds of up to $4.2 \mathrm{~km} / \mathrm{s}$. Also, repetitive operation of the two-stage guri (four plastic pellets fired at $\approx 0.5 \mathrm{~Hz}$ ) was demonstrated for the first time in preliminary tests. The equipment and operation are described, and experimental results and some comparisons with a theoretical model are presented.

\footnotetext{
"Research sponsored by the Office of Fusion Energy, U.S. Department of Energy, under contract DEAC05-84OR21400 with Martin Marietta Energy Systems, Inc.
} 


\section{INTRODUCTION}

A recent paper ${ }^{1}$ describes a developmental effort at Oak Ridge National Laboratory (ORNL) in which a simple two-stage light gas gun was constructed and used to study the acceleration of small, light projectiles to high speeds. One application of this technology is high-speed injection of frozen macroscopic (millimeter-size) pellets of hydrogen isotopes for fueling magnetically confined plasmas for controlled thermonuclear fusion research. During the last ten years, conventional single-stage pellet injectors have been used to inject frozen hydrogen and deuterium pellets into plasmas on numerous tokamak experiments. 2,3 Recently, ORNL. used a simple pneumatic "pipe gun" for the first demonstration of the formation and acceleration of tritium pellets in the Tritium Systems Test Assembly at Los Alamos National Laboratory. 4 Tritium pellet injection is an integral part of the fueling systems planned for future fusion experiments and reactors. With recent pellet fueling applications extending to the larger tokamak experiments, such as the Tokamak Fusion Test Reactor (TFTR) ${ }^{5}$ and the Joint European Torus (JET), 6 it is clear that higher velocities are desirable. Faster pellets can provide more central fueling by penetrating deeper into the larger, hotter plasmas associated with these and future fusion devices. The performance of the basic single-stage light gas gun is limited by the sound speed of the room-temperature propellant gas to $\approx 2 \mathrm{~km} / \mathrm{s}$. Ts overcome this limitation, the two-stage gun technique relies on a piston moving at high speed in a cylinder to adiabatically compress the second-stage propellant gas to high pressure and temperature in a chamber located at the gun breech. The background and basic theory of the two-stage light gas gun are discussed in detail in Refs. 1 and 7.

Two research groups in Europe 8,9 are also developing the two-stage pneumatic technique for high-speed pellet injection; in experiments conducted by 
one of these groups, ${ }^{9}$ a deuterium pellet was accelerated to a velocity of $3.8 \mathrm{~km} / \mathrm{s}$ using the sabot technique to protect the pellet from the high accelerating forces and hot gas. The sabots also limit the erosion of the pellet in the gun barrel, which becomes an issue at higher velocities. However, it is no simple task to separate the pellet from the sabct at high speeds and to deliver only the pellet to the plasma. A reliable technique to accomplish the stripping action is yet to be demonstrated. These experimenters report peak acceleration limits of $(5-6) \times 10^{6} \mathrm{~m} / \mathrm{s}^{2}$ for a bare deuterium peilet without fracturing (corresponding to speeds of $\approx 2.5-2.8 \mathrm{~km} / \mathrm{s}$ ).

In tests of the prototype ORNL two-stage light gas gun carried out since the work reported in Ref. 1, the performance with plastic projectiles was improved slightly. The gun was then modified to allow operation with cryogenic pellets composed of frozen hydrogen isotopes and some preliminary repetitive operation with room-temperature plastic projectiles. A 4-mm-diam pellet size was chosen for these tests, since it is applicable to large piesent-day tokamak experiments; in fact, pellet fueling systems on both TFTR and JET are equipped with this pellet size. Thus, the projectile mass of interest is in the range of 5-20 mg (hydrogen, deuterium, and tritium ice have densities of $0.087,0.20$, and $0.32 \mathrm{~g} / \mathrm{cm}^{3}$, respectively). The use of the sabot technique dictates heavier projectiles, depending on the specific design. The equipment and its operation are described, and experimental results and some comparisons with a theoretical model are presented.

\section{DESCRIPTION OF EQUIPMENT}

Figure 1 is a schematic of the prototype ORNL two-stage device; the upgraded device is shown in Fig. 2. Physical parameters of the guns and operating test ranges are listed in Taole I. For both versions, a 2.2-I reservoir provides the gas (typically helium) to accelerate the piston in a 1 -m-long pump tube. The downstream gas is 
compressed as the piston travels down the pump tube and thus driven to high pressure, which propels the projectile in the second driving stage. The projectile does not start to move until the pressure is high enough to overcome the wall shear stress of the tightly fitting pellet $=70$ bar for nylon projectiles and $\geq 20$ bar for hydrogen pellets); the pellet is then accelerated through the 1-m-long gun barrel into a vacuum injection line. In the prototype gun, a burst disk separates the two stages and acts to initiate the acceleration process (the thickness of the burst disk determines the rupture pressure); a high-flow-type fast valve serves the same function for the new gun. Operation of the prototype gun is relatively simple. First, a projectile is loaded through the gun breech into the gun barrel; this requires partial disassembly of the apparatus. Next, after reassembly, the pressure in the second stage is adjusted to the desired level ( $<1$ bar). Finally, the pressure in the first stage is raised to a level high enough to rupture the burst disk (>10 bar).

The upgraded version of the gun offers more operating options. In addition to the use of a fast valve in place of a rupture disk, the new gun (Fig. 2) incorporates two major modifications. A cryostat (inside a vacuum enclosure) was added to the gun barrel. Liquid helium flowing through the cooling channels of the cryostat, which surrounds the gun barrel, provides the capability of freezing hydrogen or deuterium pellets in situ. The pellet feed gas can be introduced from either side of the cryostat (through the pump tube or from the downstream side of the gun barrel) or from both sides at once. The construction and operation of such guns are described in detail in Refs. 10 and 11. For this application, only the temperature of the cryostat $(\approx 10 \mathrm{~K})$ is controlled; no attempt is made to control the pellet length. The other modification is a pneumatically activated, two-position slide mechanism (located inside a second vacuum enclosure). This mechanism essentially separates the pump tube and the gun barrel. For cryogenic operation, the slide acts as a shutoff valve in position 2 (Fig. 2) and separates the cryostat and pellet from the room-temperature helium 
propellant gas. It is moved into position 1 immediately before firing of the gun; the open hole in the slide bar is accurately aligned with the gun barrel. For roomtemperature operation with plastic pellets, single projectiles can be loaded manually into the hole when the slide bar is in position 2, and the gun can be fired after the slide bar is returned to position 1.

A recent addition is an automatic loading mechanism that can be used to remotely load a pellet into the slide mechanism when it is in position 2 . This loading mechanism can hold up to 36 4-mm-diam pellets and can be reloaded manually within a few minutes. The autematic loading mechanism can easily load pellets at a rate of $1 \mathrm{~Hz}$. O-ring type seals and a pneumatic clamp allow adequate sealing at the interface between the pump tube, the slide mechanism, and the gun barrel during the firing phase, when high peak pressures are generated in the gun. The pneumatic clamp releases when the slide is moved to minimize the possibility of damage to the O-rings. Details of the mechanical design are not shown in Fig. 2.

The experiment is equipped with instrumentation (some of which is shown in Figs. 1 and 2) to evaluate gun performance. On the prototype gun, pressure transducers were located at both ends of the pump tube (one directly in front of the piston and one at the tube end, as shown in Fig. 1), and a shock accelerometer was also located at the end of the pump tube. The upgraded version of the gun has a pressure transducer only at the upstream end of the pump tube and a shock accelerometer at the downstream end of the pump tube (these are not shown in Fig. 2). From the data provided by these transducers, the flight time for the piston to travel the $\approx 1-\mathrm{m}$ length can be evaluated for both versions of the gun. Instrumentation located in the vacuum injection line provides velocity and photographic information to document each pellet shot thoroughly. Light barriers through which pellets pass supply timing data for accurately evaluating pellet speeds. At the end of the injection line, a target plate intercepts the pellets and indicates pellet dispersion and integrity; this target also 
provides timing data for velocity measurements, since it is equipped with a shock accelerometer. A CAMAC data acquisition system is used to record and archive the transient data for each shot.

\section{EXPERIMENTAL RESULTS}

Some new results obtained with the prototype gun (Fig. 1) are described first. Nylon was used for both the piston and the projectile in this experiment. The piston was $25.4 \mathrm{~mm}$ in diameter and $41.3 \mathrm{~mm}$ long (with a $60^{\circ}$ taper on the front) vith a mass of $19.5 \mathrm{~g}$; the projectile was $3.9 \mathrm{~mm}$ in diameter and $2.8 \mathrm{~mm}$ long with a mass of $35 \mathrm{mg}$. Data from a representative shot (shot 1210) are listed in Table II. Helium was used as the drivirig gas in both stages, with a burst pressure in the first stage of $\approx 72$ bar and a prefill pressure in the second stage of 0.8 bar. The pressure pulse measured at the downstream end of the pump tube for this shot is shown in Fig. 3; the peak pressure of 3670 bar $(53,200 \mathrm{psi})$ is the highest value measured in this study with a 25.4-mm-diam pump tube. The full width at half-maximum (FWHM) of the pressure pulse is $\approx 50 \mu \mathrm{s}$. The piston traveled the $\approx 1-\mathrm{m}$ length of the pump tube in $3.20 \mathrm{~ms}$, as determined from the data in Fig. 4. The peak pressure (72 bar) measured at the start of the pump tube corresponds to the time at which the piston passes the first pressure transducer $(6672 \mu \mathrm{s})$; the shock accelerometer indicates the time of piston impact at the other end (9872 $\mu \mathrm{s})$. The impact occurs at the same time as the peak pressure (Fig. 3). The measured speed for shot 1210 was $4.5 \mathrm{~km} / \mathrm{s}$, which is also the highest value recorded to date in these experiments. Acceleration rates were not measured in these studies. However, a rigorous theoretical model, described in Sec. IV, appears adequate to estimate this important parameter. Some comparisons of the experimental data and the results obtained from the model are also discussed in Sec. IV. 
Some limited acceleration tests were carried out in which the 25.4-mrn-diam pump tube was replaced with a 50.8-mm-clam tube. However, the resulting peak pressures (approaching 7000 bar) were high enough to cause yielding of some mechanical components. Another gun of this size is being prapared so that the performance with a larger pump tube can be sufficiently evaluated.

The upgraded version of the two-stage gun was used for all other experiments described in this paper. The standard piston for these tests was similar in physical geometry to the one on the prototype gun, but it was constructed of polyimide with $15 \%$ graphite filler by weight (supplied as Vespel ${ }^{\circledR}$ SP-21 by E. I. du Pont de Nemours \& Co., Inc.). The polyimide is slightly heavier than nylon, so that the piston

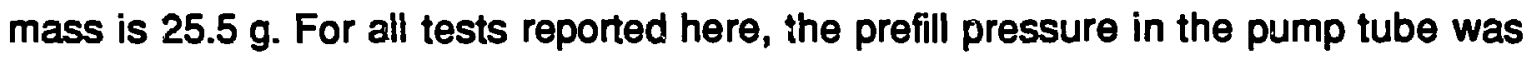
0.8 bar, as in shot 1210. In previous experiments, ${ }^{1}$ this was found to be an optimum operating condition; that is, it produced good gun performance with minimum impact damage to the piston. Thus, the key experimental variable was the reservoir pressure for the first stage. The fast valve that replaced the rupture disk of the prototype gun was originally designed for a smaller (19-mm-diam) pump tube and somewhat limited the gas flow in these tests; thus, the peak pressure measured at the upstream pump tube end was appreciably less than the initial reservoir pressure. Hundreds of deuterium pellets were fabricated and shot using the pipe gun cryostat/two-stage driver apparatus shown in Fig. 2, with an emphasis on documenting the velocity limit. The experimental data for four shots are listed in Table II.

Photographs of in-flight pellets for shots 5041 and 5064 are shown in Fig. 5. These pellets were $\approx 3.0 \mathrm{~mm}$ in diameter and $4.5 \mathrm{~mm}$ long, as determined from the photographs. The measured speeds for these shots were 1.60 and $2.60 \mathrm{~km} / \mathrm{s}$, respectively. Pellet erosion in the gun barrel accounts for the reduction in pellet diameter (gun barrel bore of $3.9 \mathrm{~mm}$ ). These pictures were taken $\approx 10 \mathrm{~cm}$ 
downstream of the gun muzzle. Most pellets were photographed within $1 \mathrm{~cm}$ of the muzzle where a dense gas cloud tends to obscure the pellet and can make it difficult to evaluate the pellet quality. When the photographs were rot definitive, the signals from the light gates and the impact pattern on the target plate were used to confirm the pellet condition (intact or fragmented). The highest speed recorded for an intact pellet was $2.85 \mathrm{~km} / \mathrm{s}$; the data for this shot (5089) are listed in Table II. However, broken pellets were often observed when the measured speed exceeded $\approx 2.5 \mathrm{~km} / \mathrm{s}$. This is consistent with results reported by other research groups. 8,9 Even though this limit may be improved slightly by optimizing the gun design and operating parameters, it appears that the sabot technique will be required to consistently attain intact pellets at speeds of $>3 \mathrm{~km} / \mathrm{s}$. Testing of different sabot schemes has begun at ORNL, and one European group 9 has already been working on this approach for several years.

In some limited tests, 3.9-mm-diam, 2.8-m-long lithium hydride (LiH) pellets were shot with the gun. These pellets were machined from stock material at the Oak Ridge Y-12 Plant . The density of the material is $0.78 \mathrm{~g} / \mathrm{cm}^{3}$; thus, the LiH projectiles weighed $\approx 26 \mathrm{mg}$. In shots 5164 and 5165 , speeds of 3.2 and $4.2 \mathrm{~km} / \mathrm{s}$ were recorded, respectively. The corresponding pressures in the first-stage resenvoir for these shots were 69 and 110 bar. The information for shot 5165 is summarized in Table II. High-speed "impurity injection" of such materials has been proposed for studying transport phenomena in tokamak plasmas.

In other tests, repetitive operation of the two-stage gun was demonstrated with $50-\mathrm{mg}$ plastic pellets ( $3.9 \mathrm{~mm}$ in diameter by $3.5 \mathrm{~mm}$ long). The weight of these test pellets is probably close to the combined mass of a hydrogen isotope pellet and a sabot. The autematic loading mechanism mentioned earlier was used to fire four pellets at $=0.5 \mathrm{~Hz}$. The first-stage reservoir pressure was 62 bar for this series of shots. Pellet velocities were $=2 \mathrm{~km} / \mathrm{s}$. In these tests, each pellet was remotely loaded 
and fired in a manually controlled sequence. The gas handling capability of the pumping system limited the frequency and the number of shots. However, the preliminary results are encouraging and suggest that operation at $\geq 1 \mathrm{~Hz}$ is feasible with the proper instrumentation and controls and gas handling systems.

For all but the most severe iest conditions, a piston could be used for 10-50 shots before significant erosion was observed. Even when pistons showing appreciable wear (up to $\approx 0.3 \mathrm{~mm}$ decrease in diameter) were used, the performance of the gun did not deteriorate significantly. For projectile speeds of $<3 \mathrm{~km} / \mathrm{s}$, the present piston design would probably be adequate for hundreds of shots. More robust pistons, probably made of metal or metal alloys, will probably be needed for reliable operation and long lifetimes in higher velocity ranges.

\section{Comparison of Data to Gas Dynamics Theory}

A two-stage Lagrangian gas dynamics code 7 is used to model the interior ballistics of the two-stage light gas gun system. This code has the following capabilities: (1) Lagrangian formulation of the finite difference representation of the onedimensional differential equations of continuity, motion, and energy, (2) treatment of shocks that form in the pump tube and barrel by the artificial viscosity method of von Neumann and Richtmyer, 12 which spraads out shocks due to dissipative effects such as viscosity and heat conduction, (3) modeling of either real (variable specific heat) or ideal gases, and (4) accounting for nonideal effects, including (a) piston friction and plastic deformation, (b) heat transfer from gas to wall via the Reynolds analogy 13 method, and (c) smooth-wall, constant surface roughness or constant gas friction factor.

Extensive computer modeling runs have been made for both nylon pellets (mass of $35 \mathrm{mg}$ ) and deuterium pellets (mass of $10 \mathrm{mg}$ ). Experimental data and 
some inputs to and outputs from the code are shown in Table II. As pointed out previously, the velocity in shot 1210 is the highest recorded to date $(4.5 \mathrm{~km} / \mathrm{s})$. The code indicates that the gas is driven to temperatures approaching $10,000 \mathrm{~K}$ during the compression. Figure 3 is a cumparison of the downstream pump tube pressure from the code calculations with the experimentally measured values; agreement is very good during the ramp-up phase. The peak pressure predicted by the code (4690 bar) is somewhat larger than the measurid peak value (3670 bar). However, the flat profile of the pressure pulse at the neak on this shot (Fig. 3) stogests that the pressure transducer or data acquisition system probably missed the maximum value. For the computer runs, the first-stage initial pressure was adjusted so that the piston travel time was comparable to that measured from diagnostic signals at each end of the pump tube ( $\approx 1-\mathrm{m}$ travel distance). This adjustment usually involved a somewhat lower first-stage pressure input for the code than that estimated experimentally. However, the output from the pressure transducer immediately after the rupture of the burst disk (or the opening of the fast valve for the new gun) was quite noisy and somewhat difficult to interpret. With this constraint, the code generally predicts the gun performance very well; for shot 1210 , the predicted pellet speed is within $=8 \%$ of the measured value. The estimated peak acceleration for this shot is $4.5 \times 10^{7} \mathrm{~m} / \mathrm{s}^{2}$.

The code was also used to evaluate shots with deuterium pellets. A typical frozen pellet should weigh $=10 \mathrm{mg}$. Table II lists experimental data and code inputs and outputs for four deuterium shots. In the new gun, the downstream pump tube pressure was not measured; the components at the pump tube/slide mechanism/gun barrel interface limited access to that area. In general, the code predicts the gun performance very well; calculated speeds are within $6 \%$ of the measured values. For operation with higher pump tube pressures (as in shots 5064, 5088, and 5089), the maximum acceleration indicated by the code is $6.7 \times 10^{6} \mathrm{~m} / \mathrm{s}^{2}$. The pellet velocity and acceleration rate calculated from the code are shown in Fig. 6 as a function of 
the pellet position in the gun barrel. For many shots at these conditions and even at slightly lower first stage pressures, the pellets were often observed to be broken at the gun muzzle. This is consistent with the acceleration limit of $(5-6) \times 10^{6} \mathrm{~m} / \mathrm{s}^{2}$ reported by other researchers. 8,9 For reliable operation at higher speeds, protective sabots to encase the hydrogenic pellets will probably be required, as noted previously.

The code indicates that gas friction is the dominant nonideal effect, with heat transfer and piston friction accounting for only $10-30 \%$ of the total energy loss. This conclusion agrees with recent theoretical work at the Risø National Laboratory in Denmark. ${ }^{14}$ For the calculations presented here, the gas friction was determined by measuring the actual surface roughness, $\varepsilon$, of the pump tube and gun barrel and then calculating a friction factor based on the local Reynolds number and the measured $E / D$, where $D$ is the relevant pipe diameter.

\section{SUMMARY}

The objective of this research is to develop a high-speed hydrogen isotope pellet injector based on the two-stage light gas gun concept. This technique offers the capability of accelerating small, light projectiles to speeds of $\approx 5 \mathrm{~km} / \mathrm{s}$, as demonstrated in these studies. Pellets composed of frozen hydrogen isotopes can be accelerated to velocities approaching $3 \mathrm{~km} / \mathrm{s}$; however, to achieve higher speeds, the use of sabots appears to be necessary to protect the relatively weak hydrogen ice from the high peak pressures and acceleration forces, as well as the hot gases. Repetitive operation appears to be feasible at rates of $=1 \mathrm{~Hz}$ or greater. The next major step in this development effort is to combine the present ORNL two-stage gun with a cryogenic extruder for hydrogen ice (also developed at ORNL). 15,16 These components form the basis for a repetitive gun that can perform at rates of $=1 \mathrm{~Hz}$ or greater and 
accommodate sabots. The engineering problems associated with reliable repetitive operation, the sabot design and separation mechanism, and the high gas throughput will require a significant effort before such a system can demonstrate the reliability attained by present pellet injectors (see, e.g., Ref. 17). Other possible applications of this technology include (1) high-speed impurity injection of materials, such as LiD, into tokamak plasmas for transport studies and (2) the investigation of erosion and/or impact damage to different materials from small, high-speed projectiles.

\section{ACKNOWLEDGMENTS}

This research was sponsored by the Office of Fusion Energy, U.S. Department of Energy, under contract DE-AC05-840R21400 with Martin Marietta Energy Systems, Inc.

\section{REFERENCES}

1. S. K. Combs, S. L. Milora, C. R. Foust, M. J. Gouge, D. T. Fehling, and

D. O. Sparks, J. Vac. Sci. Technol. A 7 (3), 963 (1989).

2. S. L. Milora, J. Fusion Energy 1,15 (1981).

3. S. L. Milora, J. Vac. Sci. Technol. A 7 (3), 925 (1989).

4. P. W. Fisher, M. L. Bauer, L. R. Baylor, S. K. Combs, L. E. Deleanu, D. T. Fehling. C. A. Foster, M. J. Gougz, S. L. Milora, D. D. Schuresko, D. O. Sparks, and J. C. Whitson, J. Vac. Sci. Technol. A 7 (3), 938 (1989).

5. S. L. Milora, G. L. Schmidt, V. Anunasalam, M. G. Bell, M. Bitter, C. E. Bush, S. K. Combs, P. C. Etthimion, A. C. England, E. Fredrickson, R. J. Goldston, B. Grek, L. R. Grisham, R. H. Hawryluk, W. Heidbrink, H. Hendel, K. W. Hill, D. Johnson, L. C. Johnson, P. H. LaMarche, R. Little, D. Mansfield, D. McCune, K. McGuire, D. M. Meade, D. Mueller, E. B. Nieschmidt, D. K. Owens, H. Park, A. 
T. Ramsey, J. F. Schivell, S. Sesnic, F. Stauffer, B. L. Stratton, G. Taylor, H. H.

Towner, R. M. Wieland, J. B. Wilgen, and M. C. Zarnstorff, Plasma Phys. Controlled Fusion 28, 1435 (1986).

6. S. L. Milora, G. L. Schmidt, T. C. Jernigan, L. R. Baylor, S. K. Combs, W. A. Houlberg, D. Schissel, P. Colestock, G. Hammett, M. Zarnstorff, P. Kupschus, A. Cheetham, B. Denne, M. Gadeberg, C. Gowers, A. Gondhalekar, and B. Tubbing, Europhys. Conf. Abstr. 12B, Part I, 147 (1988).

7. M. J. Gouge, S. K. Combs, P. W. Fisher, and S. L. Milora, Rev. Sci. Instrum. 60 (4), 570 (1989).

8. A. Reggion, R. Carlevaro, G. Riva, G. Daminelli, F. Scaramuzzi, A. Frattolillo, L. Martinis, P. Cardoni, and L. Mori, J. Vac. Sci. Technol. A 6 (4), 2556 (1983).

9. K. Sonnenberg, P. Kupschius, J. Helm, D. Flory, and F. Zacchia, in Fusion Technology 1988, editors A. M. Van Ingen, A. Nijsen-Vis, and H. T. Klippel (Elsevier Science Publishers B.V., North-Holland, 1989), Vol. 1, p. 715.

10. S. K. Combs, S. L. Milora, and C. R. Foust, Rav. Sci. Instrum. 57, 2636 (1986).

11. P. W. Fisher, S. L. Milora, S. K. Combs, R. V. Carlson, and D.O. Coffin, Fusion Technol. 14, 339 (1988).

12. J. von Neumann and R. D. Richtmyer, J. Appl. Phys. 21, 232 (1950).

13. Turbulent Flows and Heat Transfer, C. C. Lin, editor, Vol. 5 of High Speed Aerodynamics and Jet Propulsion (Princeton University Press, Princeton, N.J., 1959).

14. Ming-Lun Xue, Risø Report M-2663, October 1987.

15. C. A. Foster, J. Vac. Sci. Technol. A 1 (2), 952 (1983).

16. S. K. Combs, S. L. Milora, C. R. Foust, C. A. Foster, and D. D. Schuresko, Rev. Sci. Instrum. 56, 1173 (1985).

17. S. K. Combs, T. C. Jernigan, L. R. Baylor, S. L. Milora, C. R. Foust, P. Kupschus, M. Gadeberg, and W. Bailey, Rev. Sci. Instrum. 60 (8), 2697 (1989). 
Table I. Parameters for ORNL two-stage light gas guns

First stage

$\begin{array}{ll}\text { Volume }\left(\mathrm{cm}^{3}\right) & 2250 \\ \text { Length }(\mathrm{m}) & \approx 0.42 \\ \text { Inside diameter }(\mathrm{mm}) & \approx 82 \\ \text { Initial pressurea (bar) } & 10-110\end{array}$

Activation mechanism

Burst disk or fast valve

Second stege

Volume $\left(\mathrm{cm}^{3}\right)$

Length $(\mathrm{m})$

Inside diameter (mm)

Initial pressure (bar)

500

1

25.4

$<1$

Gun barrel

Length $(m)$

1

Inside diameter $(\mathrm{mm}) \quad$. $\quad 3.9$

Piston mass ${ }^{b}$ (g)

10-50

apressure in the first-stage reservoir before triggening of activation mechanism.

bIncludes ail piston weights tested in the ORNL experiments. 
Table II. Experimental data for test shots and results from gas dynamics model

(Values in parentheses are inputs for or results from code calculations)

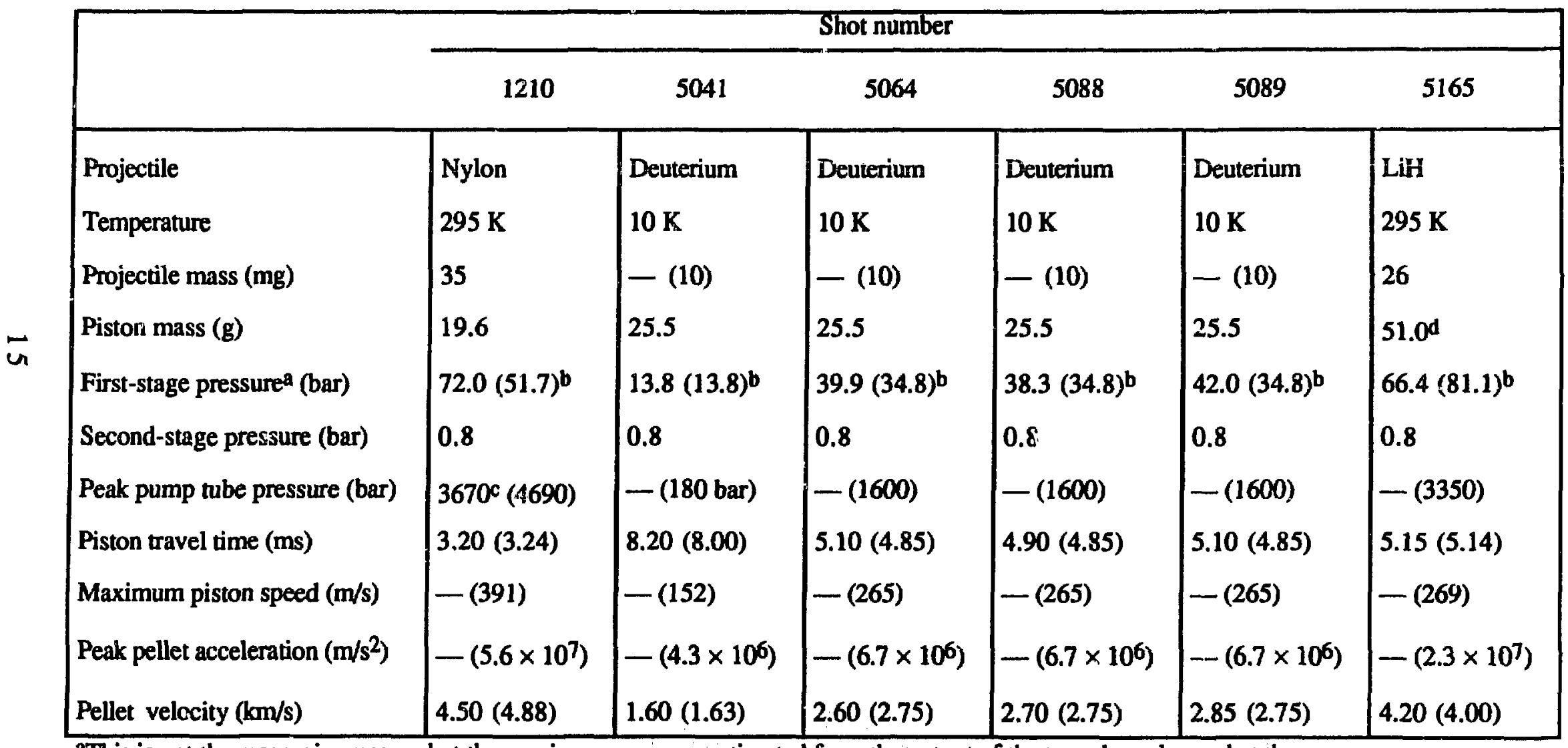

aThis is not the reservoir pressure but the maximum pressure estimated from the output of the transducer located at the upstream end of the pump tube.

bFirst-stage pressure for the code calculation; it was adjusted so that the calculated piston travel time closely matched the

experimentally measured value; for shots 5064, 5088, and 5089, the same pressure was used, so the code results are the same.

CFlat profile of pressure pulse at peak on this shot suggested that instrument or data acquisition may have missed maximum value.

Two $25.5 \mathrm{~g}$ pistons were used in pump tube for this shot; it was modeled as a single piston. 


\section{FIGURE CAPTIONS}

Fig. 1. Schematic of the ORNL original two-stage light gas gun.

Fig. 2. Schematic of the ORNL upgraded two-stage light gas gun.

Fig. 3. Pressure measured at downstream end of pump tube during a high-speed shot of a 35-mg nylon projectile; calculated results from a gas dynamics code are also shown.

Fig. 4. Data traces for a high-speed shot: (a) pressure measured at the start or upstream end of pump tube and (b) output of shock accelerometer located at the downstream end of the pump tube.

Fig. 5. In-flight photographs of deuterium pellets for two test shots; pictures ware taken $\approx 10 \mathrm{~cm}$ downstream of the gun muzzle.

Fig. 6. Pellet velocity and acceleration curves calculated frrom a gas dynamics model for a high-speed deuterium test shot . 


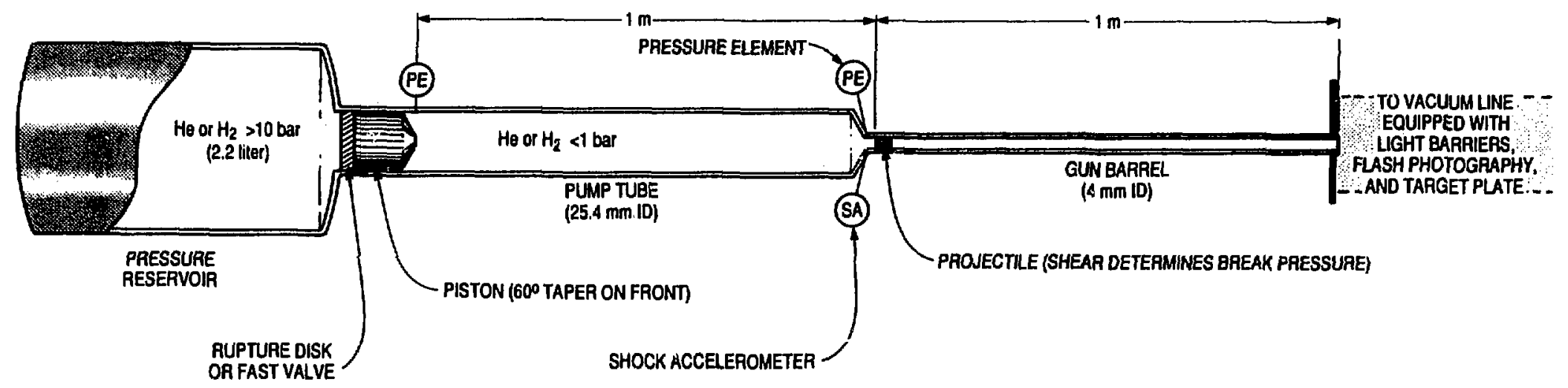

Fig. 1 


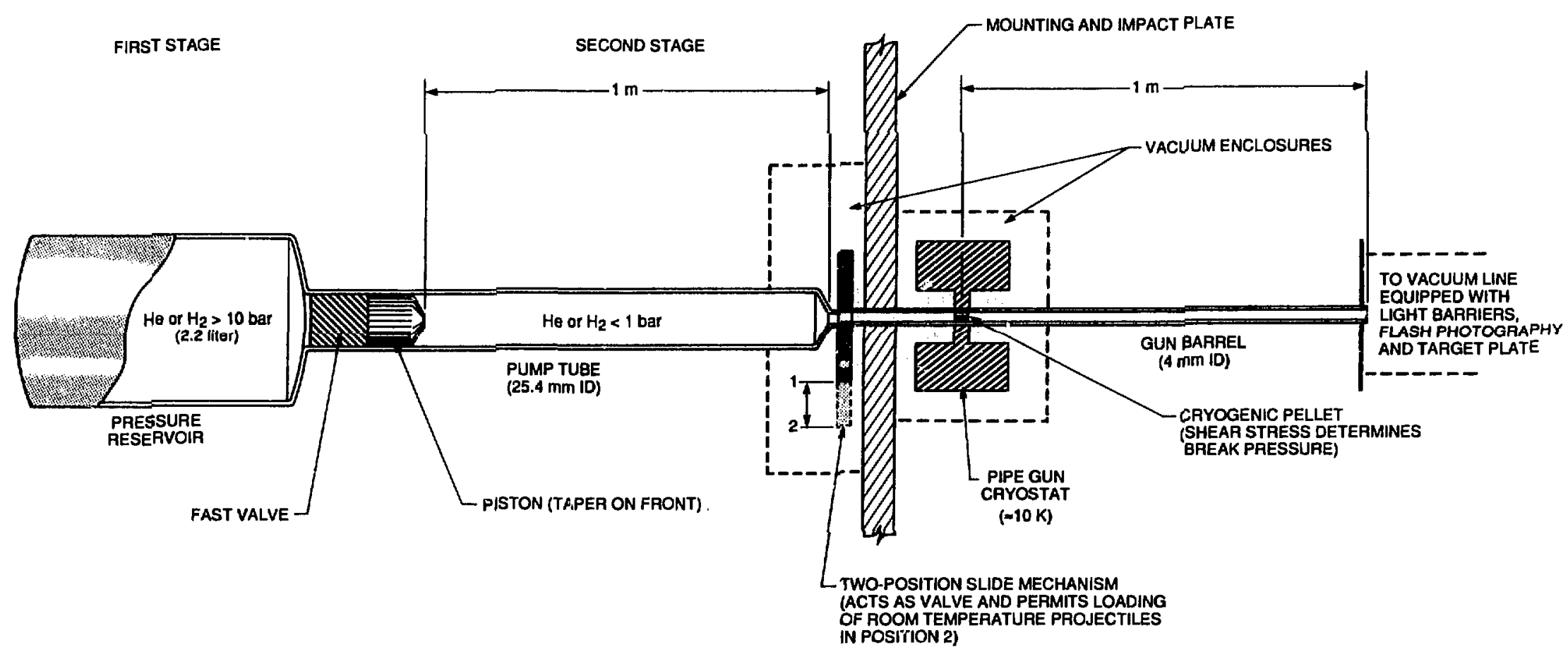

Fig. 2 
DOWNSTREAM PUMP TUBE PRESSURE (bar)

$\frac{7}{\omega}$

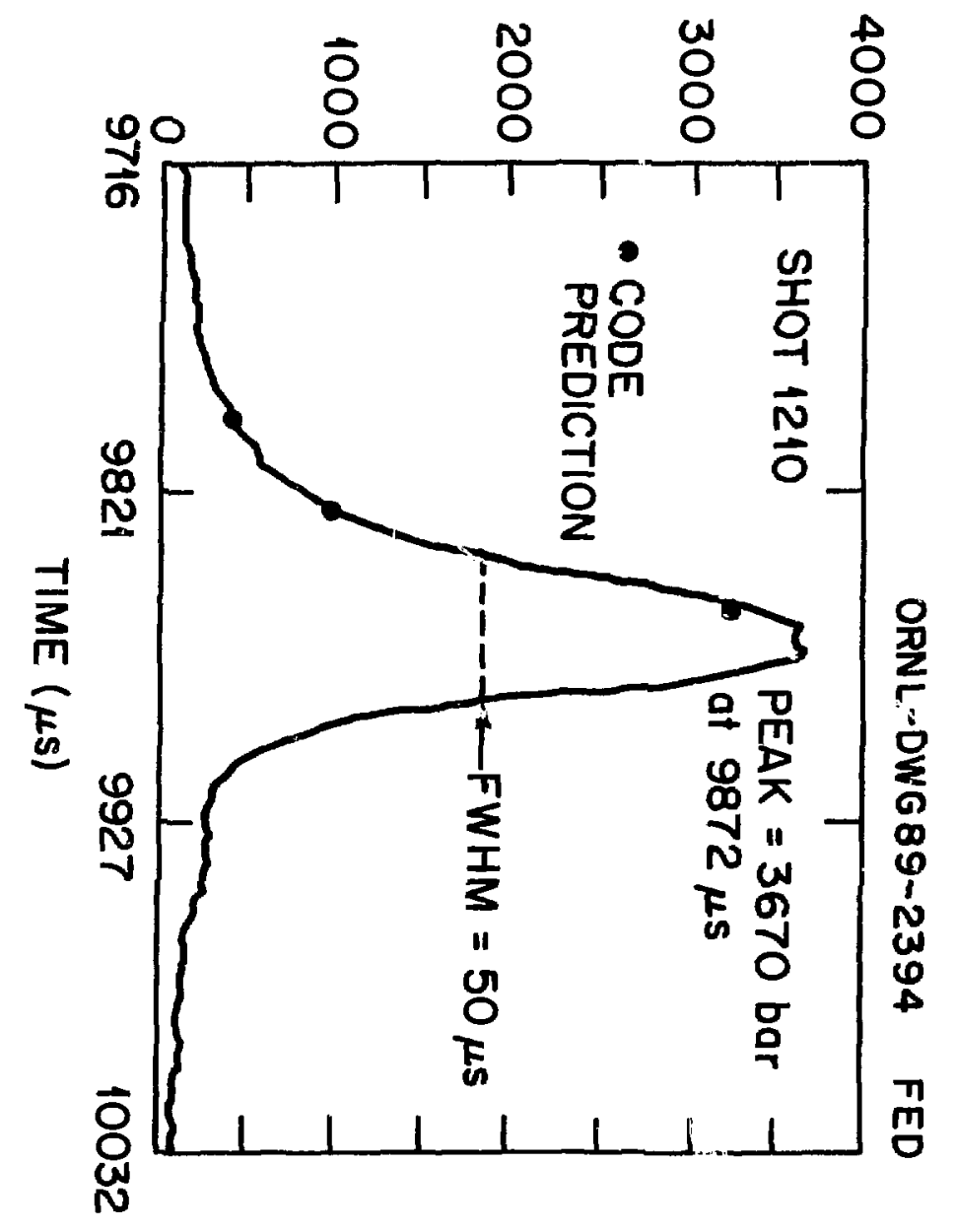




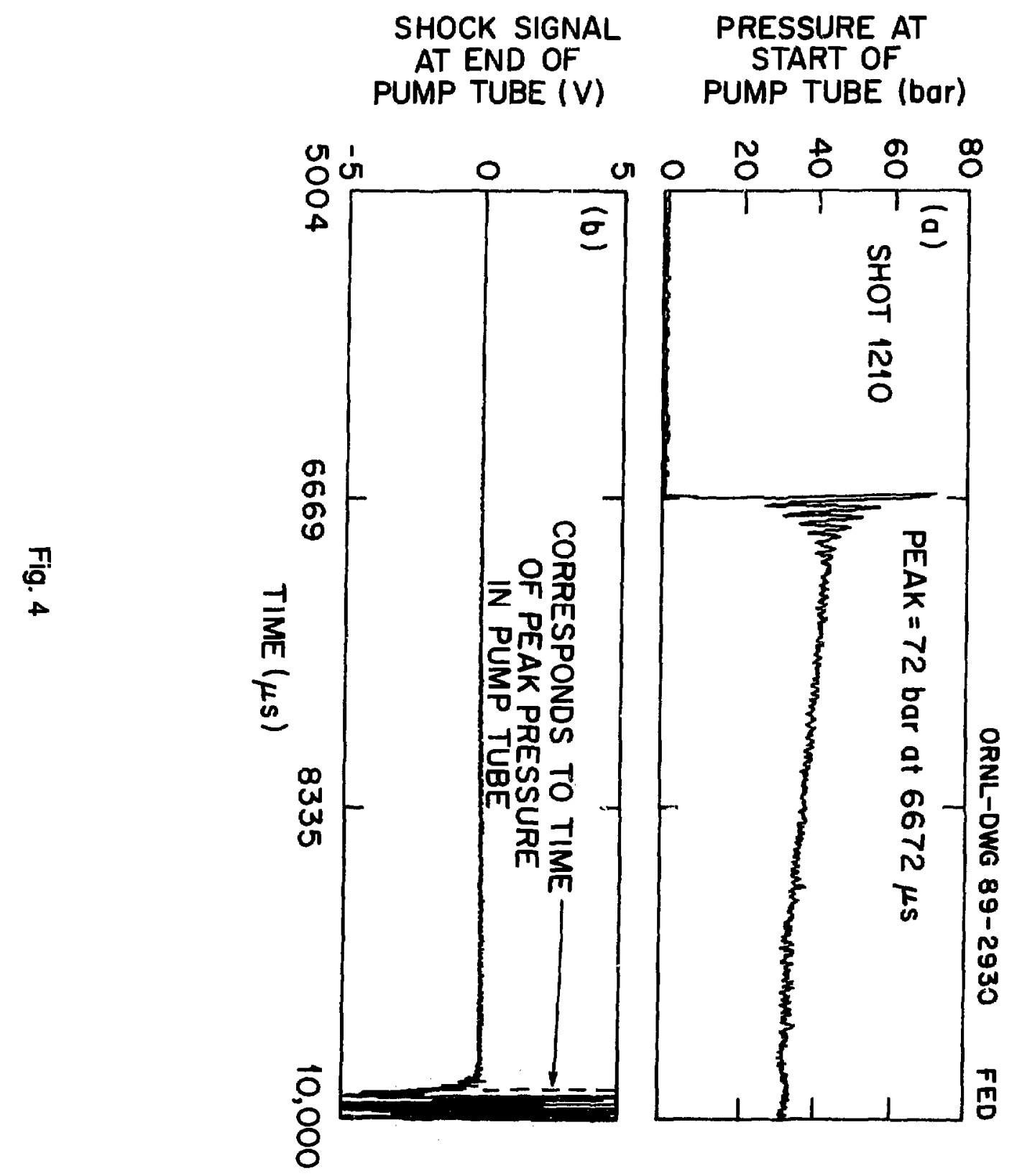




\section{ORNL-PHOTO 7294-89 FED}

SHOT 5041

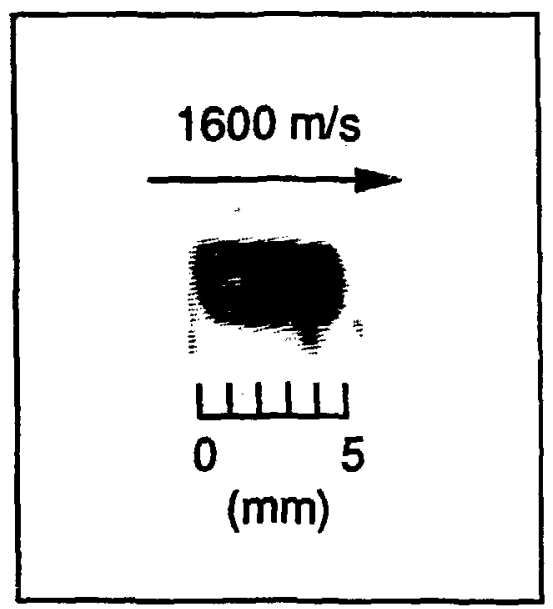

SHOT 5064

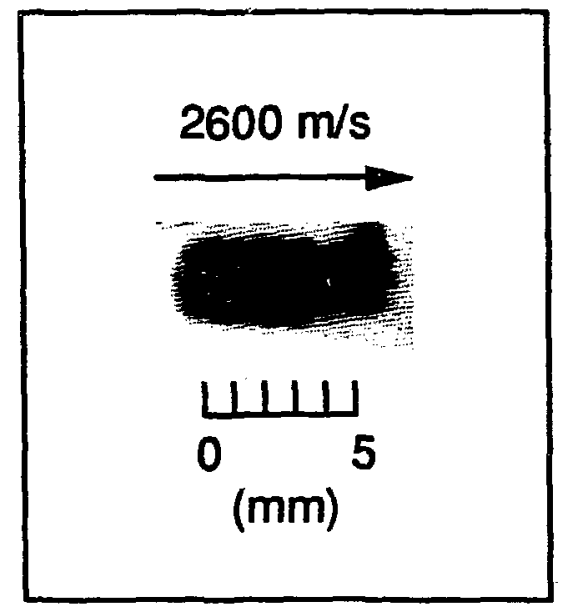

Fig. 5 


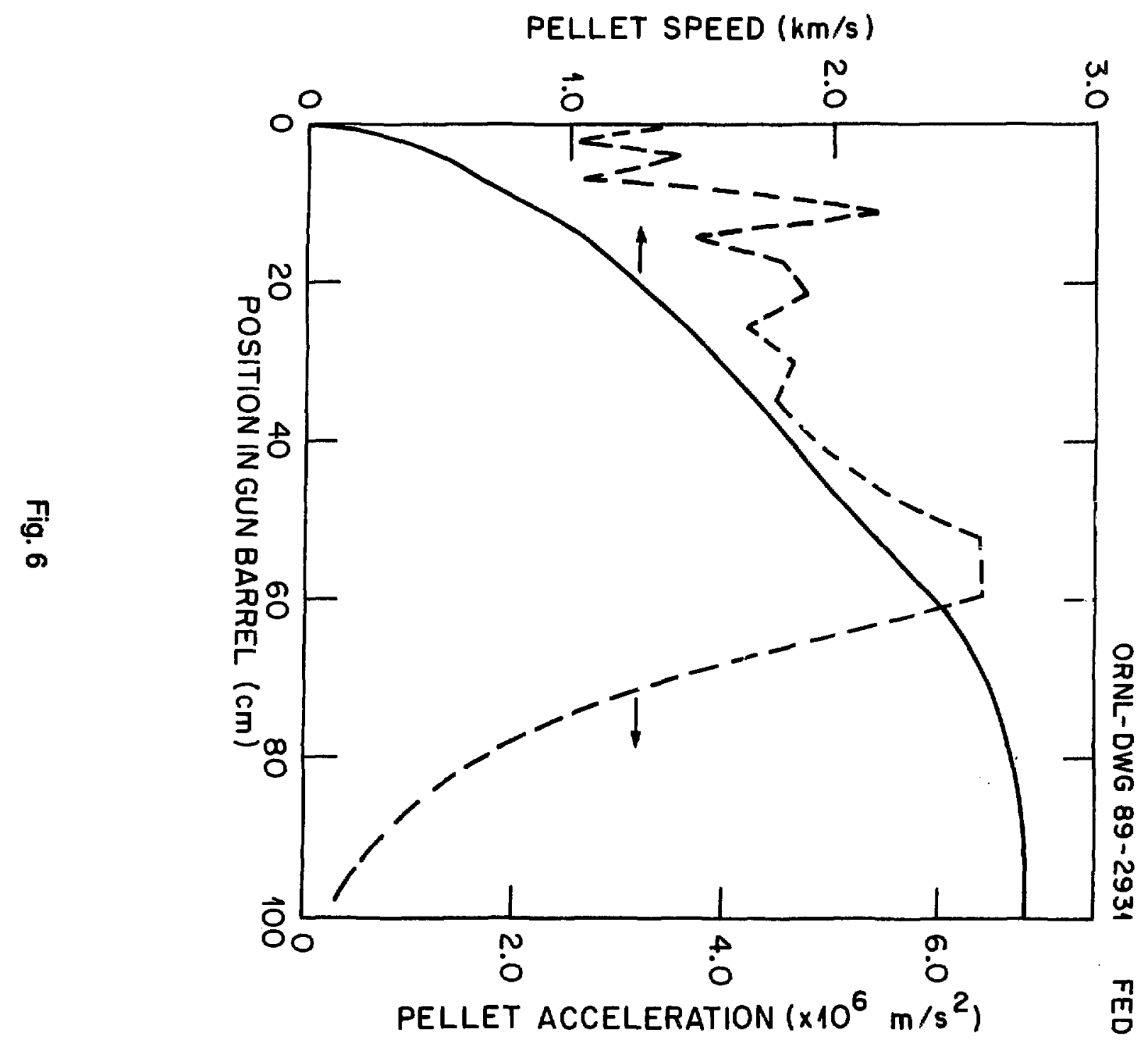

